\title{
EVALUASI KEBUTUHAN RUANG PARKIR PADA RUMAH SAKIT KELAS C DI KOTA PALANGKA RAYA
}

\author{
Ari Widya Permana ${ }^{1}$, Noviyanthy Handayani ${ }^{2}$, Norseta Ajie Saputra ${ }^{3}$ \\ Program Studi Teknik Sipil, Universitas Muhammadiyah Palangkaraya \\ lari.w.permana@gmail.com, ${ }^{2}$ vianthy84@yahoo.com, ${ }^{3}$ norseta.ajie@gmail.com
}

\begin{abstract}
ABSTRAK
Rumah Sakit Ibu dan Anak Yasmin Kota Palangka Raya adalah salah satu Rumah Sakit Swasta Kelas C di Kalimantan Tengah. RSIA Yasmin menjadi salah satu Rumah Sakit yang ramai dikunjungi setiap harinya. Pada jam-jam berkunjung terjadi lonjakan kebutuhan ruang parkir di RSIA Yasmin, sehingga tidak tertampungnya kendaraan yang akan menggunakan areal parkir tersebut. Penelitian ini bertujuan untuk mengevaluasi kapasitas lahan parkir pada RSIA Yasmin Kota Palangka Raya dan memberikan usulan perbaikan kepada pihak RSIA Yasmin. Data primer diperoleh dari hasil pengamatan langsung yang meliputi pengukuran jumlah petak parkir, luas areal parkir, pencacahan waktu dan jumlah kendaraan keluar - masuk. Selanjutnya data dianalisis untuk mendapatkan karakteristik parkir yang meliputi volume parkir, akumulasi parkir, durasi parkir, pergantian parkir, kapasitas parkir, dan indeks parkir. Berdasarkan hasil analisis, akumulatif parkir kendaraan maksimum terjadi pada hari senin, indeks parkir sepeda motor melebihi $100 \%$, berarti kebutuhan parkir melebihi daya tampung/kapasitas parkir normal. Usulan perbaikan yaitu dengan menggunakan basement sebagai lahan parkir untuk menambah kapasitas ruang parkir serta penataan pola parkir dan sirkulasi parkir.
\end{abstract}

Kata Kunci: akumulasi parkir, durasi parkir, indeks parkir, kapasitas ruang parkir, volume parkir

\begin{abstract}
Yasmin Mother and Child Hospital in Palangkaraya City is one of the Class C Hospitals in Central Kalimantan. Yasmin Hospital has become one of the most visited hospitals every day. During visiting hours there was an increase in the need for parking spaces at Yasmin RSIA, so that vehicles that would not use the parking area were not accommodated. This study aims to evaluate the capacity of the parking lot at the RSIA Yasmin Palangka Raya City and provide suggestions for improvement to the Yasmin RSIA. Primary data were obtained from direct observations which included measurements of the number of parking lots, parking area, time count and circulation of the number of vehicles. Furthermore, the data were analyzed to obtain parking characteristics which include parking volume, parking accumulation, parking duration, parking change, parking capacity, and parking index. Based on the results of the analysis, the maximum accumulated vehicle parking occurs on Monday, the motorcycle parking index exceeds 100\%, meaning that parking needs exceed normal parking capacity. The proposed improvement is to use the basement as a parking lot to increase the capacity of parking spaces and to arrange parking patterns and parking circulation.
\end{abstract}

Keywords: parking capacity, parking cumulative, parking duration, parking index, parking volume 


\section{PENDAHULUAN}

Rumah Sakit merupakan salah satu pusat kegiatan yang banyak dikunjungi oleh penduduk karena satu atau lain hal. Rumah Sakit juga tidak terlepas dari masalah perparkiran yang dapat mengganggu tingkat kenyamanan dalam proses pelayanan yang diberikan oleh pihak rumah sakit. Meningkatnya angka pasien sudah tentu membawa dampak meningkatnya kepemilikan kendaraan yang menyebabkan meningkatnya kebutuhan parkir

Rumah Sakit Ibu dan Anak Yasmin Kota Palangka Raya adalah salah satu Rumah Sakit Swasta Kelas C di Kalimantan Tengah. Dengan jangkauan layanannya sebagian besar warga Kota Palangka Raya, serta juga warga kabupaten di Kalimantan Tengah. RSIA Yasmin menjadi salah satu Rumah Sakit yang ramai dikunjungi setiap harinya. Rumah Sakit yang memiliki luas lahan sebesar $1.889 \mathrm{~m} 2$ dengan pembagian total luas lahan parkir berkisar $572 \mathrm{~m} 2$ ini berdasarkan kondisi di lapangan masih belum memenuhi kebutuhan ruang parkir.

Dari hasil pengamatan awal, disaat jam-jam berkunjung terjadi lonjakan kebutuhan ruang parkir di RSIA Yasmin, lonjakan yang terjadi pada jam-jam tertentu terkadang mengakibatkan tidak tertampungnya kendaraan yang akan menggunakan areal parkir tersebut. Oleh karena itu maka diperlukan evaluasi kapasitas lahan parkir pada Rumah Sakit Ibu dan Anak Yasmin Kota Palangka Raya.

\section{KAJIAN PUSTAKA}

\section{Pengertian Parkir}

Menurut Undang-Undang RI No. 22 Tahun 2009 tentang Lalu Lintas dan Angkutan Jalan, parkir adalah keadaan kendaraan berhenti atau tidak bergerak untuk beberapa saat dan ditinggalkan pengemudinya. Berhenti adalah keadaan dimana kendaraan tidak bergerak untuk sementara dan tidak ditinggalkan pengemudinya

\section{Satuan Ruang Parkir}

Kebutuhan ruang parkir ditentukan berdasarkan Satuan Ruang Parkir (SRP). Satuan Ruang Parkir adalah ukuran luas efektif untuk meletakkan kendaraan (mobil penumpang, truk, atau sepeda motor), termasuk ruang bebas dan lebar buka pintu. Penentuan satuan ruang parkir dapat dilihat pada Tabel 1.

Tabel 1. Penentuan Satuan Ruang Parkir

\begin{tabular}{|c|c|c|}
\hline No & Jenis Kendaraan & SRP dalam $\mathrm{m}^{2}$ \\
\hline 1 & $\begin{array}{c}\text { a. Mobil Penumpang } \\
\text { Gol I }\end{array}$ & $2,30 \times 5,00$ \\
\hline & $\begin{array}{c}\text { b. Mobil Penumpang } \\
\text { Gol II }\end{array}$ & $2,50 \times 5,00$ \\
\hline 2 & $\begin{array}{c}\text { c. Mobil Penumpang } \\
\text { Gol III }\end{array}$ & $3,00 \times 5,00$ \\
\hline 3 & Bus / Truk & $3,40 \times 12,50$ \\
\hline & Sepeda Motor & $0,75 \times 2,00$ \\
\hline
\end{tabular}

Sumber : Pedoman Teknis Dirjen Perhubungan Darat, 1996

\section{Metode Menentukan Permintaan Parkir}

Adapun metode untuk penentuan kebutuhan jumlah petak parkir (Tamin, 2008) dapat diketahui berdasarkan:

1. Metode berdasarkan kepemilikan kendaraan Metode ini mengasumsikan adanya hubungan antara luas lahan parkir dengan jumlah kendaraan yang tercatat dipusat kota. Semakin meningkat jumlah penduduk, maka kebutuhan lahan parkir akan semakin meningkat karena kepemilikan kendaraan meningkat.

2. Metode berdasarkan luas lantai bangunan Metode ini mengasumsikan bahwa kebutuhan lantai parkir sangat terkait dengan jumlah kegiatan yang dinyatakan dalam besaran luas lantai bangunan dimana kegiatan tersebut dilakukan, misalnya perbelanjaan, perkantoran, kampus, dan lain-lain.

3. Metode berdasarkan selisih terbesar antara kedatangan dan keberangkatan kendaraan.

Kebutuhan lahan parkir didapatkan dengan menghitung akumulasi terbesar pada suatu selang waktu pengamatan. Akumulasi parkir adalah jumlah kendaraan parkir pada suatu tempat pada selang waktu tertentu, dimana jumlah kendaraan tidak akan pernah sama pada suatu tempat lainnya dari waktu ke waktu.

Persyaratan permintaan ruang parkir menurut Pedoman Teknis Dirjen Perhubungan Darat No.272/HK.105/96 kebutuhan ruang parkir untuk Rumah Sakit adalah 0,2-1,3 SRP/tempat tidur 


\section{Karakteristik Parkir}

Berdasarkan karakteristik parkir, akan dapat diketahui kondisi perparkiran yang terjadi pada daerah studi seperti mencakup volume parkir, akumulasi parkir, lama waktu parkir, pergantian parkir, penyediaan ruang parkir, kapasitas parkir, dan indeks parkir (Munawar, 2004).

\section{Volume Parkir}

Volume parkir adalah jumlah kendaraan yang masuk areal parkir selama jam-jam pengamatan (dianggap satu hari dan mengunakan fasilitas parkir). Rumus yang digunakan adalah:

$\mathrm{Vp}=\mathrm{Ei}+\mathrm{X}$

dengan: $\mathrm{Ei}=$ kendaraan yang masuk lokasi parkir

$\mathrm{Vp}=$ volume parkir

$\mathrm{X}=$ kendaraan yang sudah ada di lokasi parkir

\section{Akumulasi Parkir}

Akumulasi parkir adalah jumlah total dari kendaraan yang parkir selama periode tertentu (Hobbs, 1997). Akumulasi ini dapat dijadikan sebagai ukuran kebutuhan ruang parkir di lokasi. Rumus yang digunakan adalah:

$$
\mathrm{AP}=\mathrm{Ei}-\mathrm{Ex}+\mathrm{X}
$$

dengan: $A p=$ Akumulasi parkir

$\mathrm{Ei}=$ Jumlah kendaraan yang masuk ke lokasi parkir

Ex = Jumlah kendaraan yang keluar ke lokasi parkir

$\mathrm{X}=$ Jumlah kendaraan yang sudah ada di lokasi parkir

\section{Lama Waktu Parkir (Durasi Parkir)}

Durasi adalah rata-rata lama waktu yang dipakai setiap kendaraan untuk berhenti pada ruang parkir.

Rumus yang digunakan adalah:

$$
\mathrm{DP}=\mathrm{Ex}-\mathrm{En}
$$

dengan: $\mathrm{DP}=$ Durasi parkir (menit)

Ex = Waktu saat kendaraan keluar dari ruang parkir (menit).

En = Waktu saat kendaraan masuk ke ruang parkir (menit)

Kapasitas parkir

Kapasitas ruang parkir merupakan kemampuan maksimum ruang tersebut dalam menampung kendaraan, dalam hal ini adalah volume kendaraan pemakai fasilitas parkir tersebut. Rumus yang digunakan adalah:

$$
\mathrm{KP}=\mathrm{S} / \mathrm{D}
$$

dengan : KP : Kapasitas parkir (kend/jam)

\section{S : Jumlah total stall/petak resmi (petak)}

D : Rata-rata lama parkir (jam/kend)

\section{Indeks Parkir}

Indeks parkir adalah perbandingan antara akumulasi parkir dengan kapasitas ruang parkir yang tersedia. Nilai indeks parkir ini dapat menunjukkan seberapa besar kapasitas parkir yang telah terisi. Indeks parkir dirumuskan sebagai berikut:

Ip = Akumulasi Parkir / Ruang Parkir Tersedia

IP $<1$ artinya bahwa fasilitas parkir tidak bermasalah, dimana kebutuhan parkir tidak melebihi daya tampung/kapasitas normal.

IP = 1 artinya bahwa kebutuhan parkir seimbang dengan daya tampung/kapasitas normal.

IP > 1 artinya bahwa fasilitas parkir bermasalah, dimana kebutuhan parkir melebihi daya tampung/kapasitas normal.

\section{Pergantian Parkir (Turnover Parking)}

Pergantian parkir menunjukkan tingkat penggunaan ruang parkir dan diperoleh dengan membagi volume parkir dengan jumlah ruang parkir untuk periode waktu tertentu. Pergantian parkir dirumuskan sebagai berikut:

$$
\mathrm{TR}=\mathrm{Nt} / \mathrm{S}
$$

dengan: $\mathrm{TR}=$ Angka pergantian parkir (kend/jam/SRP)

$\mathrm{Nt}=$ Jumlah total kendaraan selama waktu survei (kend)

$\mathrm{S}=$ Jumlah ruang parkir (SRP)

\section{Penyediaan Parkir (Parking Supply)}

Penyediaan parkir (parking supply) atau kemampuan penyediaan parkir adalah batas ukuran banyaknya kendaraan yang dapat ditampung selama periode waktu tertentu. Rumus yang digunakan adalah:

$$
\mathrm{PS}=(\mathrm{S} \times \mathrm{Ts}) / \mathrm{D} \times \mathrm{F}
$$

dengan : PS : Daya tampung kendaraan yang dapat diparkir (kend)

$\mathrm{S}$ : Jumlah ruang parkir yang tersedia (SRP)

Ts : Lama waktu survei (jam)

D : Rata-rata lamanya parkir (jam/kend)

$\mathrm{F}$ : Faktor pengurangan akibat pergantian parkir, nilai $0,85-0,90$.

Kebutuhan Ruang Parkir

Kebutuhan ruang parkir adalah jumlah tempat yang dibutuhkan untuk menampung kendaraan yang membutuhkan parkir berdasarkan fasilitas dan 
fungsi dari sebuah tata guna lahan. Rumus yang dipakai adalah sebagai berikut:

$$
\mathrm{S}=(\mathrm{Nt} \times \mathrm{D}) /(\mathrm{T} \times \mathrm{f})
$$

dengan: $\mathrm{S}$ : Jumlah petak parkir yang diperlukan

$\mathrm{Nt}$ : Jumlah total kendaraan selama waktu survei (kend)

D : Waktu rata - rata lamanya parkir (jam/kend)

$\mathrm{T}$ : Lamanya survei (jam)

f : Faktor pengurangan akibat pergantian parkir, nilai antara $0,85 \mathrm{~s} / \mathrm{d} 0,95$.

\section{METODE PENELITIAN}

\section{Bagan Alir Penelitian}

Adapun langkah-langkah penelitian seperti pada Gambar 1.

\section{Lokasi Penelitian}

Lokasi penelitian yaitu Rumah Sakit Ibu dan Anak (RSIA) Yasmin yang berlokasi di Jl. Cilik Riwut, No. 04 KM. 1,5, Palangka Raya, Kalimantan Tengah

\section{Pengumpulan Data}

Pengumpulan data meliputi data-data yang diperlukan sebagai berikut:

\section{Data Primer}

Data primer merupakan data yang diperoleh dari hasil pengamatan langsung (survey) di lokasi sesuai dengan kondisi sesungguhnya. Adapun datadata yang berhubungan langsung dari hasil survey yang dilakukan di lokasi, yaitu :

1. Jumlah petak parkir tersedia.

2. Luas areal parkir.

3. Waktu dan Jumlah kendaraan masuk.

4. Waktu dan Jumlah kendaraan keluar.

Data Sekunder

Data sekunder merupakan data-data yang diperoleh secara tidak langsung dimana memanfaatkan data-data yang ada sebelumnya tercatat di instansi terkait dan digunakan sebagai analisa. Adapun data-data yang diperoleh dari RSIA Yasmin berupa :

1. Denah Rumah Sakit Ibu dan Anak Yasmin

2. Data CCTV di area parkir kendaraan RSIA Yasmin.

\section{Waktu Pengamatan}

Waktu pengamatan ditetapkan dengan mempertimbangkan:

\section{a. Peak Day}

Penentuan peak day biasanya di bagi dalam 3 (tiga) waktu, yaitu early week, mid week, dan week end. Untuk early week dipilih hari senin atau selasa, untuk mid week dipilih hari rabu atau kamis, sedangkan untuk weekend dipilih hari jum'at, sabtu, dan minggu.

\section{b. Peak Hour}

Penentuan peak hour dibagi dalam 3 (tiga) waktu, yaitu jam sibuk pagi, siang-sore, dan malam

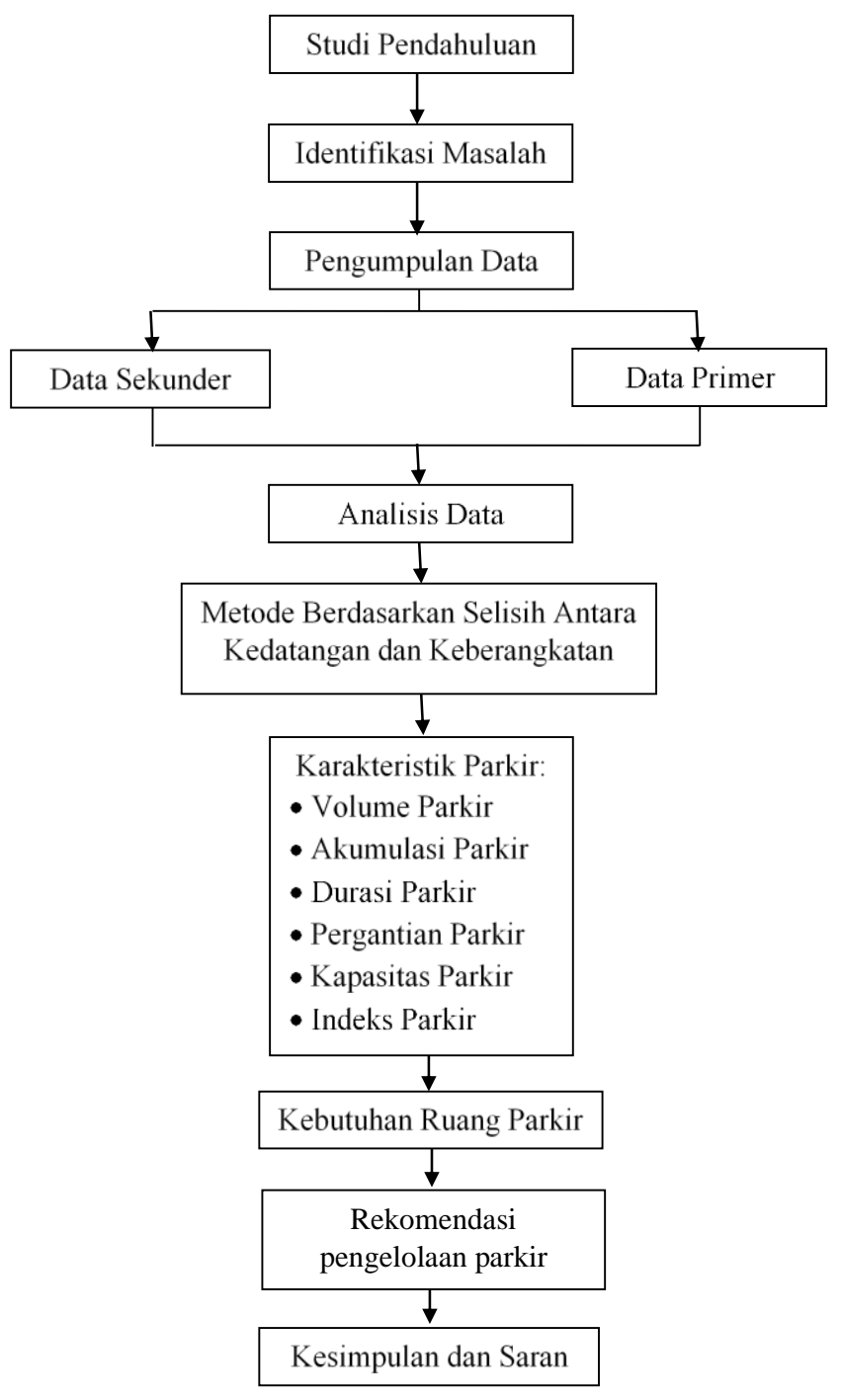

Gambar 1. Bagan Alir Penelitian 


\section{HASIL DAN PEMBAHASAN}

\section{Gambaran Umum RSIA Yasmin}

1) Status Kepemilikan: Swasta di bawah Yayasan Nihin Center

2) Luas Tanah: $1.889 \mathrm{~m}^{2}$

3) Luas Bangunan: $4.260 \mathrm{~m}^{2}$ terdiri dari 2 gedung, Gedung I berlantai 2, gedung II berlantai 1, dan gedung tengah berlantai $2+$ basement

4) Lahan Parkir:

- Parkir Off-street (dalam area): 25x17: $425 \mathrm{~m}^{2}$

- Parkir On-street (bahu jalan): $25 \times 3: 75 \mathrm{~m}^{2}$

- Basement $: 9 \times 8: 72 \mathrm{~m}^{2}$

\section{Hasil Pengamatan}

Pengamatan dilaksanakan selama 3 (tiga) hari, yaitu:

- Pada hari Sabtu, tanggal 3 Agustus 2019, pukul 07.00-21.00

- Pada hari Senin, tanggal 5 Agustus 2019, pukul 07.00-21.00

- Pada hari Kamis, tanggal 8 Agustus 2019, pukul 07.00-21.00

Adapun denah lahan parkir RSIA Yasmin seperti pada Gambar 2. Kapasitas ruang parkir yang tersedia dapat dilihat pada Tabel 2.
Tabel 2. Kapasitas parkir yang tersedia di RSIA

\begin{tabular}{|c|c|c|}
\hline No. & Kendaraan Parkir & $\begin{array}{c}\text { kapasitas parkir } \\
\text { (SRP) }\end{array}$ \\
\hline 1 & Sepeda motor & 72,00 \\
\hline 2 & Mobil & 13,00 \\
\hline
\end{tabular}

Berdasarkan Tabel 3 diketahui bahwa volume parkir tertinggi untuk sepeda motor yaitu pada hari senin. Sedangkan volume parkir tertinggi untuk mobil yaitu pada hari kamis.

Didapatkan pergantian parkir 2-3 kali pergantian. Jumlah volume parkir ini dipengaruhi oleh aktivitas perkuliahan lembaga Eltibiz, jam besuk pasien, dan jadwal praktek dokter RSIA Yasmin

Tabel 4. Hasil perhitungan durasi parkir rata-rata di RSIA Yasmin

\begin{tabular}{|c|c|c|c|c|}
\hline \multirow[t]{2}{*}{ No } & \multirow{2}{*}{$\begin{array}{l}\text { Kendaraan } \\
\text { Parkir }\end{array}$} & \multicolumn{3}{|c|}{$\begin{array}{l}\text { Durasi Parkir Rata-rata } \\
\text { (menit) }\end{array}$} \\
\hline & & Sabtu & Senin & Kamis \\
\hline 1 & Sepeda motor & 168,48 & 190,13 & 200,86 \\
\hline 2 & Mobil & 242,22 & 188,57 & 152,73 \\
\hline
\end{tabular}

Berdasarkan Tabel 4, didapatkan durasi parkir ratarata maksimum sepeda motor pada hari kamis, hal ini terkait aktivitas perkuliahan lembaga Eltibiz. Sedangkan durasi parkir rata-rata maksimum mobil pada hari sabtu, hal ini terkait jam besuk pasien pada akhir pekan

Tabel 3. Hasil pengamatan volume dan pergantian parkir di RSIA Yasmin

\begin{tabular}{|c|c|c|c|c|}
\hline No. & Kendaraan Parkir & $\begin{array}{c}\text { Volume parkir } \\
\text { (SRP) }\end{array}$ & $\begin{array}{c}\text { Kapasitas parkir } \\
\text { (SRP) }\end{array}$ & Pergantian parkir \\
\hline 1 & Sepeda motor (sabtu) & 198,00 & 72,00 & 2,75 \\
\hline 2 & Mobil (sabtu) & 27,00 & 13,00 & 2,08 \\
\hline 3 & Sepeda motor (senin) & 225,00 & 72,00 & 3,13 \\
\hline 4 & Mobil (senin) & 35,00 & 13,00 & 2,69 \\
\hline 5 & Sepeda motor (kamis) & 187,00 & 72,00 & 2,60 \\
\hline 6 & Mobil (kamis) & 44,00 & 13,00 & 3,38 \\
\hline
\end{tabular}


Evaluasi Kebutuhan Ruang.., Ari Widya Permana ${ }^{(1)}$, Noviyanthy Handayani ${ }^{(2)}$, Norseta Ajie Saputra ${ }^{(3)}$

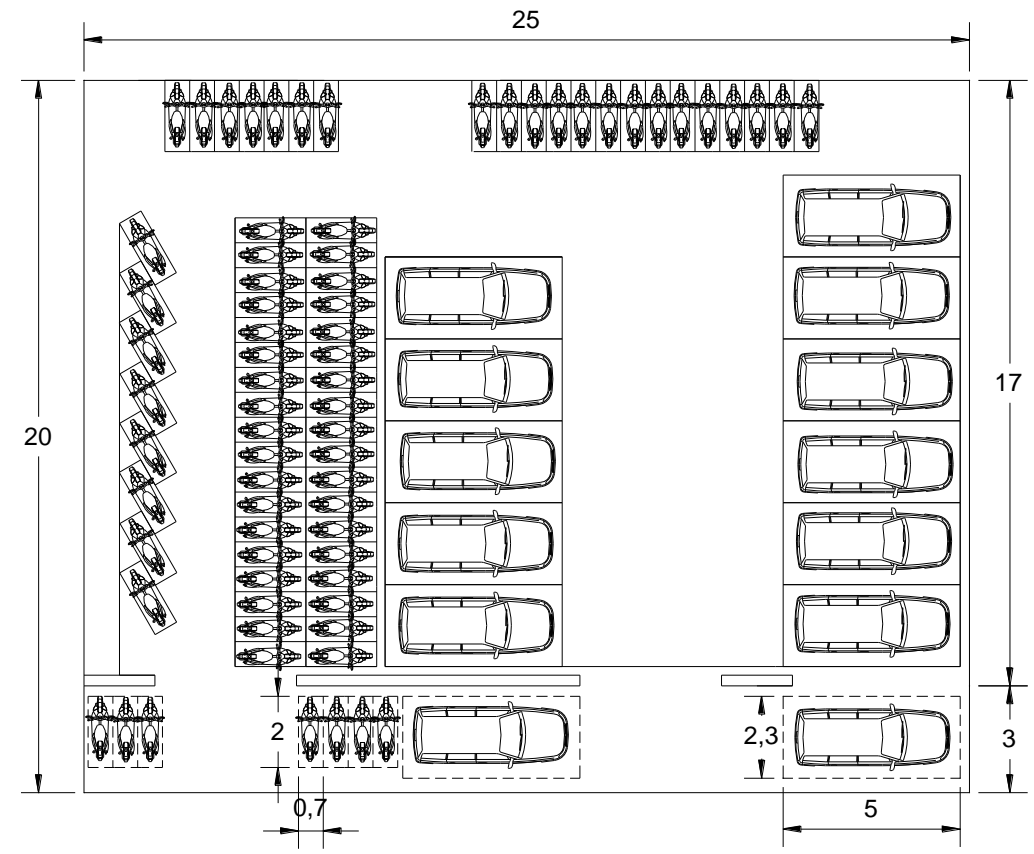

Gambar 2. Denah Lahan Parkir RSIA Yasmin

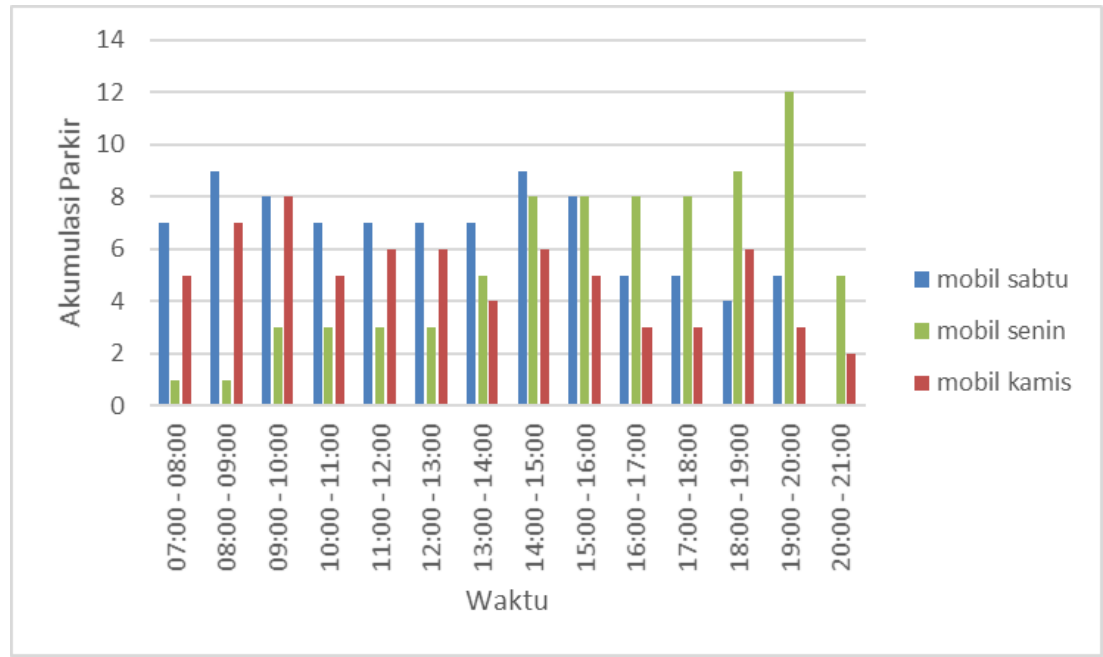

Gambar 3. Akumulasi parkir mobil di RSIA Yasmin

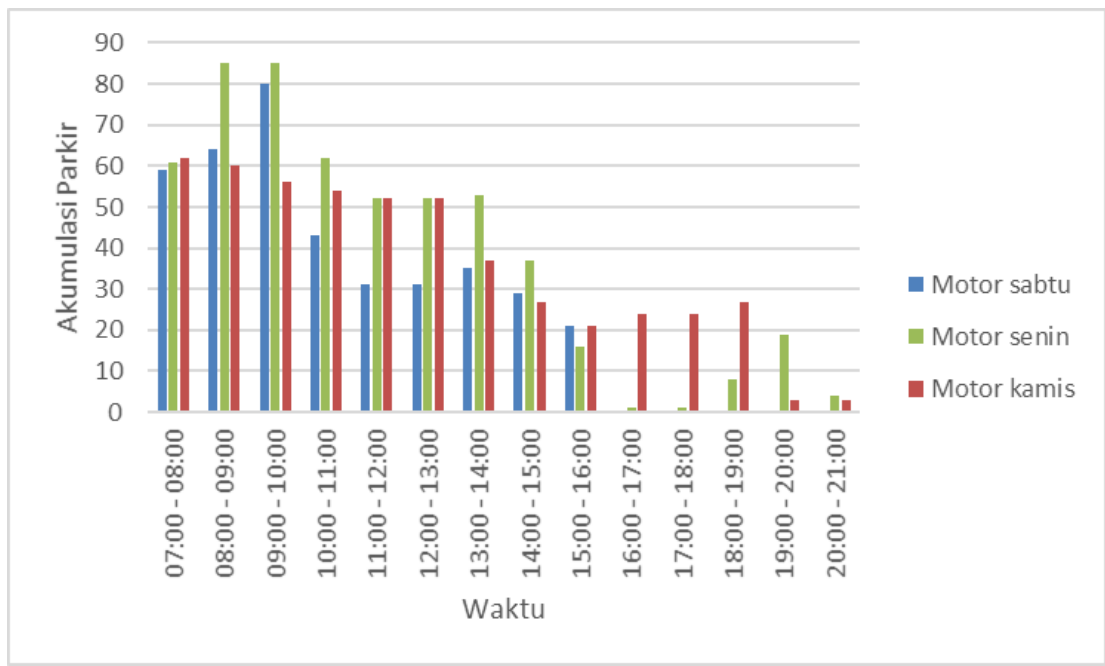

Gambar 4. Akumulasi parkir motor di RSIA Yasmin 
Evaluasi Kebutuhan Ruang.., Ari Widya Permana ${ }^{(1)}$, Noviyanthy Handayani ${ }^{(2)}$, Norseta Ajie Saputra ${ }^{(3)}$

Tabel 5. Hasil perhitungan indeks parkir di RSIA Yasmin

\begin{tabular}{|c|c|c|c|c|}
\hline No. & Kendaraan Parkir & $\begin{array}{c}\text { Akumulatif Maksimum } \\
\text { (SRP) }\end{array}$ & $\begin{array}{c}\text { Kapasitas parkir } \\
\text { (SRP) }\end{array}$ & Indeks parkir \\
\hline 1 & Sepeda motor (sabtu) & 80,0 & 72,00 & $\mathbf{1 1 1 \%}$ \\
\hline 2 & Mobil (sabtu) & 9,0 & 13,00 & $69 \%$ \\
\hline 3 & Sepeda motor (senin) & $\mathbf{8 5 , 0}$ & 72,00 & $\mathbf{1 1 8 \%}$ \\
\hline 4 & Mobil (senin) & $\mathbf{1 2 , 0}$ & 13,00 & $92 \%$ \\
\hline 5 & Sepeda motor (kamis) & 62,0 & 72,00 & $86 \%$ \\
\hline 6 & Mobil (kamis) & 8,0 & 13,00 & $62 \%$ \\
\hline
\end{tabular}

Adapun akumulasi parkir kendaraan di RSIA Yasmin seperti pada Gambar 3 dan Gambar 4.

Berdasarkan Tabel 5, dapat diketahui akumulasi parkir maksimum terjadi pada hari senin. Pada pagi hari lahan parkir sepeda motor terlihat penuh dikarenakan ada aktivitas perkuliahan lembaga
Eltibiz. Sedangkan malam hari, lahan parkir mobil penuh dikarenakan kunjungan pasien yang berkaitan dengan jadwal praktik dokter. Indeks parkir sepeda motor melebihi $100 \%$ yang berarti kebutuhan parkir melebihi daya tampung/kapasitas parkir yang tersedia

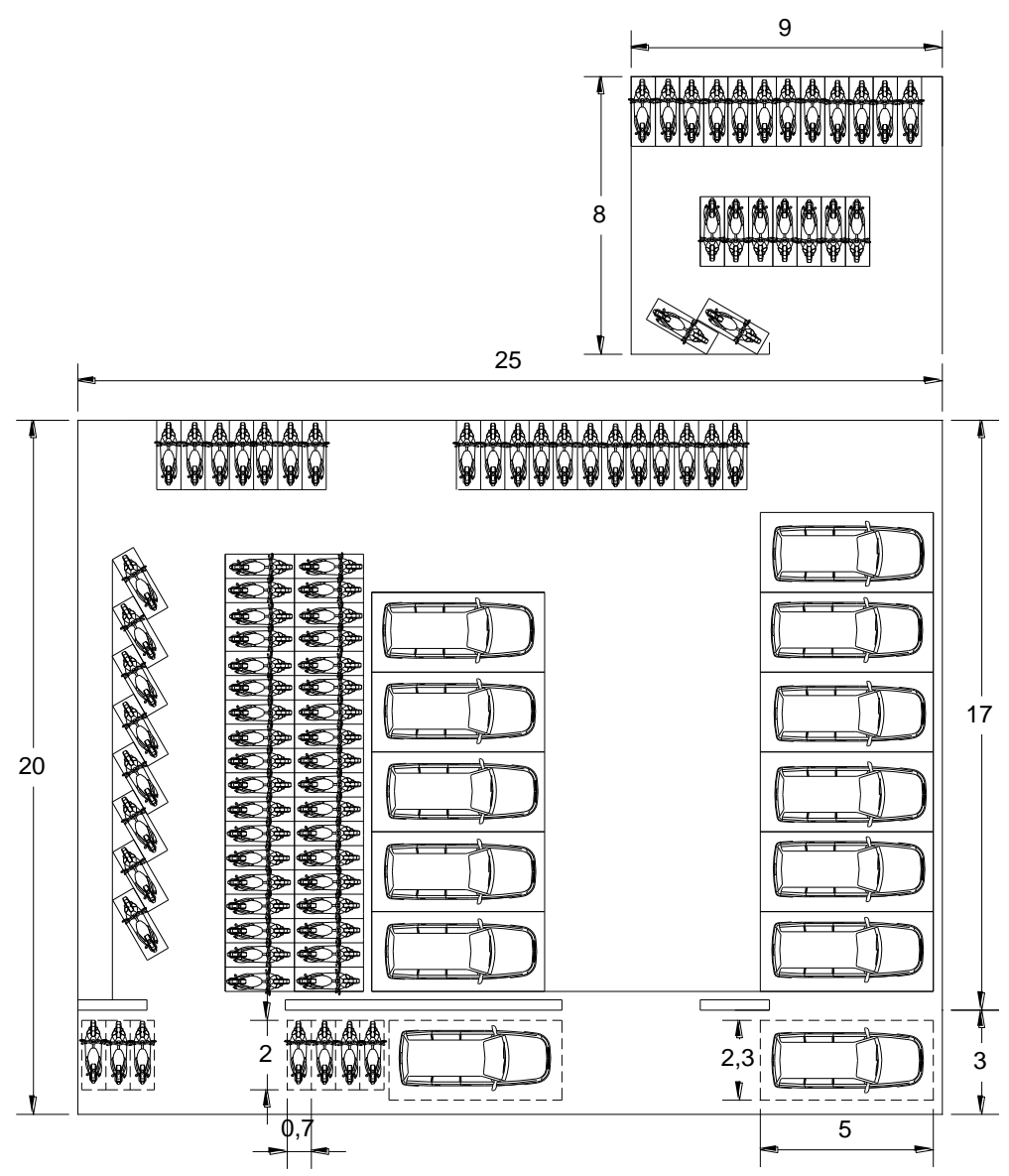

Gambar 5. Usulan pola parkir-1 (dengan Basement) 
Evaluasi Kebutuhan Ruang.., Ari Widya Permana ${ }^{(1)}$, Noviyanthy Handayani ${ }^{(2)}$, Norseta Ajie Saputra ${ }^{(3)}$

\section{Usulan Pola Parkir}

Adapun usulan pola parkir yaitu dengan memanfaatkan basement sebagai lahan parkir serta penataan pola parkir dan sirkulasi parkir seperti pada Gambar 5, Gambar 6, dan Gambar 7.

Usulan pola parkir-1

Kelebihan:

- Kapasitas Parkir Sepeda Motor: 91 SRP

- Kapasitas Parkir Mobil: 13 SRP

Kekurangan:

- Sirkulasi parkir kurang teratur dan mobil ambulans kesulitan untuk menurunkan pasien ke IGD.
Usulan pola parkir-2

Kelebihan:

- Sirkulasi parkir teratur dan memudahkan mobil ambulans untuk menurunkan pasien ke IGD

- Kapasitas Parkir Mobil: 13 SRP

Kekurangan:

- Kapasitas Parkir Sepeda Motor: 73 SRP

Usulan pola parkir-3

Kelebihan:

- Sirkulasi parkir teratur dan memudahkan mobil ambulans untuk menurunkan pasien ke IGD

- Kapasitas Parkir Sepeda Motor: 83 SRP

Kekurangan:

- Kapasitas Parkir Mobil: 12 SRP

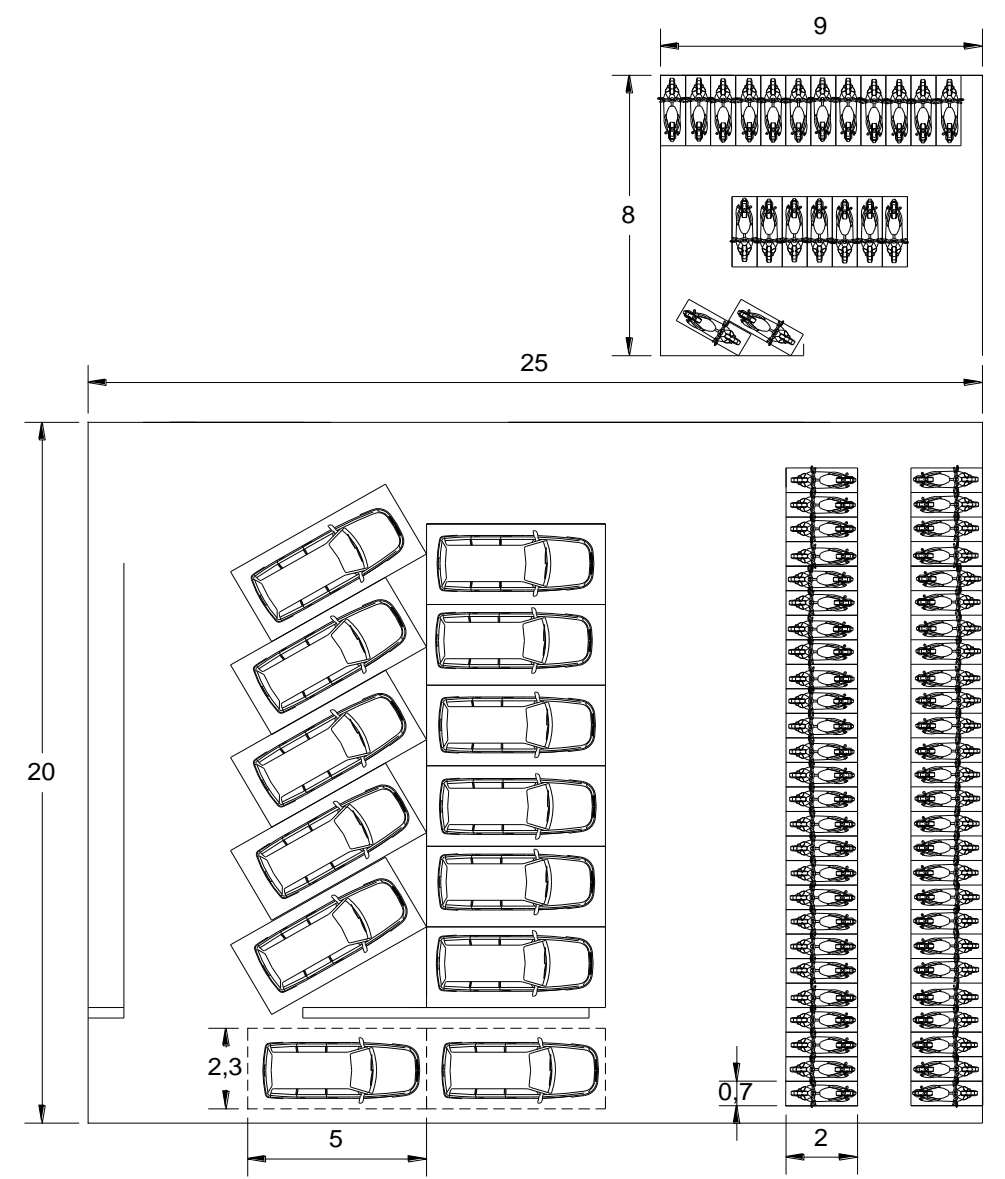

Gambar 6. Usulan pola parkir-2 (dengan Basement, penataan pola dan sirkulasi parkir) 


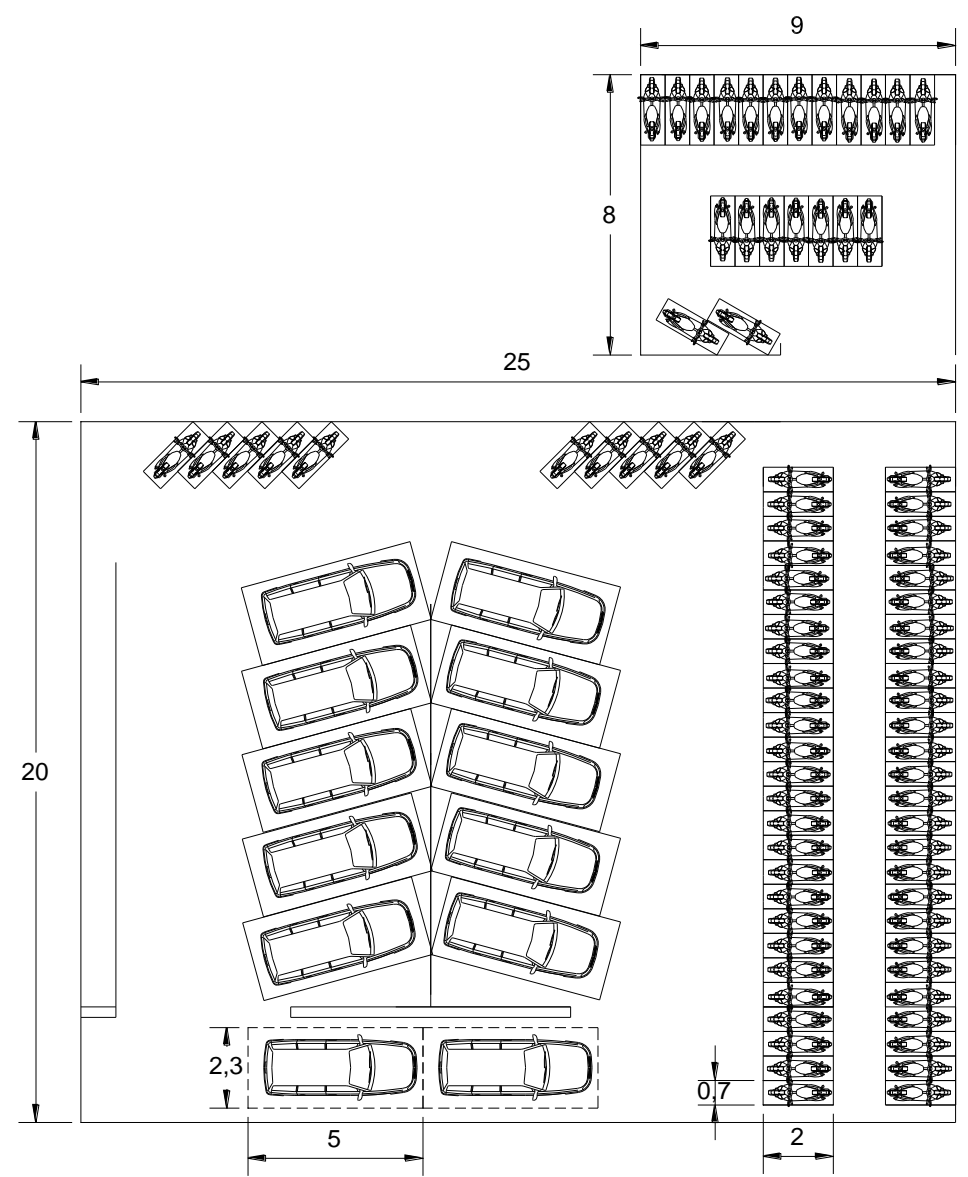

Gambar 7. Usulan pola parkir-3 (dengan Basement, penataan pola dan sirkulasi parkir)

\section{PENUTUP}

\section{Kesimpulan}

Kesimpulan yang dapat diambil yaitu:

1. Akumulatif kendaraan maksimum terjadi pada hari senin, Indeks parkir sepeda motor melebihi $100 \%$, berarti fasilitas parkir bermasalah, dimana kebutuhan parkir melebihi daya tampung/kapasitas parkir normal.

2. Usulan perbaikan yang dapat dilakukan yaitu dengan menggunakan basement sebagai lahan parkir untuk menambah kapasitas ruang parkir serta penataan pola parkir dan sirkulasi parkir

\section{Saran}

Sebagai saran untuk pihak RSIA Yasmin:

Perlu dipertimbangkan penyediaan bangunan parkir bertingkat untuk sepeda motor, terkait keterbatasan lahan parkir dan jumlah sepeda motor yg bertambah.

\section{DAFTAR PUSTAKA}

Direktorat Jenderal Perhubungan Darat. (1996). Pedoman Teknis Penyelenggaraan Fasilitas Parkir. Keputusan Direktur Jendral Perhubungan Darat. Jakarta.

Direktorat Jenderal Perhubungan Darat. (1998). Pedoman Perencanaan dan Pengoperasian Fasilitas Parkir. Direktorat Bina Sistem Lalu Lintas Angkutan Kota. Jakarta.

Hobbs, F. D. (1995). Perencanaan dan Teknik Lalu Lintas, Gadjah Mada University Press, Yogyakarta

Munawar, Ahmad. (2004). Manajemen Lalu Lintas Perkotaan, Beta Offset, Jogjakarta.

Tamin, O.Z. (2008). Perencanaan dan Permodelan Transportasi. Institut Teknologi Bandung. Bandung

Undang Undang Republik Indonesia No. 22 tahun 2009 tentang Lalu Lintas dan Angkutan Jalan 